\title{
INTERAKSI JENIS GALUR DAN MULSA TERHADAP PERTUMBUHAN TANAMAN KACANG BAMBARA (Vigna subterranea $(\mathrm{L})$. Verdcourt)
}

\author{
INTERACTION OF STRAIN AND MULCH TYPES TO \\ BAMBARA GROUNDNUT (Vigna subterranea (L). Verdcourt) \\ Asifatul Khanifah ${ }^{1 *}$, Endah Sri Redjeki ${ }^{2}$ Rahmad Jumadi $^{3}$ \\ $1^{*}, 2,3$ Program Studi Agroteknologi Fakultas Pertanian Universitas Muhammadiyah \\ Gresik. \\ Jln. Sumatra No. 101 GKB Gresik 61121 - Jawa Timur \\ *Email :asifa@gmail.com, endah.sriredjeki@umg.ac.id,rahmad@umg.ac.id
}

\begin{abstract}
ABSTRAK
Kacang bambara adalah salah satu tanaman jenis kacang-kacangan yang dikembangkan di Indonesia karena memiliki gizi yang kompetitif. Upaya meningkatkan hasil tanaman kacang bambara di lakukan melalui penanaman berbagai jenis galur kacang bambara dan jenis mulsa. Penelitian ini bertujuan mengetahui interaksi jenis galur dan mulsa pada tanaman kacang bambara (Vigna subterranea (L). Penelitian ini dilaksanakan di jln Pesantren Rt 01 Rw 02 Desa Pengulu, Kecamatan Sidayu, Kabupaten Gresik Jawa Timur, pada ketinggian $7 \mathrm{~m}$ dpl pada bulan Juni - Agustus 2020. Penelitian menggunakan dua faktor, Faktor pertama yaitu jenis galur $(G)$ yang terdiri atas 2 (dua) taraf perlakuan galur Jawa Barat (G1), galur Gresik (G2). Faktor kedua yaitu jenis mulsa (M) terdiri atas 3 (tiga) yaitu, mulsa plastik (M1), mulsa brangkasan kacang bambara 6 ton/ha (M2), mulsa jerami padi 6 ton/ha (M3). Analisis data menggunakan analisis sidik ragam lebih lanjut apabila terdapat perbedaan nyata pada uji F 5\%, dilanjutkan dengan Uji Duncan's multiple range test pada taraf $5 \%$. Untuk mengetahui keeratan hubungan dua variabel atau lebih digunakan uji korelasi. Hasil penelitian menunjukkan terdapat interaksi nyata perlakuan jenis galur dan mulsa pada variabel tinggi tanaman pada umur pengamatan $2 \mathrm{mst}, 4 \mathrm{mst}$, dan $6 \mathrm{mst}$. Tinggi tanaman terbaik ditunjukkan oleh kombinasi perlakuan mulsa brangkasan kacang bambara dan galur Gresik (M2G2)
\end{abstract}

Kata Kunci : galur gresik, kacang bambara, mulsa brangkasan kacang bambara.

\section{ABSTRACS}

Bambara groundnut is a type of legume that develop in Indonesia because of its competitive nutrition. Increasing the yield of bambara groundnut is carried out by planting various kinds of bambara bean lines and types of mulch. This study aims to determine the interaction of the types of lines and mulch on the bambara groundnut (Vigna subterranea (L). This research was carried out at Jln Pesantren Rt 01 Rw 02 Pengulu Village, Sidayu District, Gresik Regency, East Java, at an altitude of $7 \mathrm{~m}$ above sea level in June - August 2020. The study used two factors; the first factor was the type of line $(\mathrm{G})$ which consisted of 2 (two) treatment levels of West Java (G1) lines, and Gresik (G2) lines. The second factor 
was the type of mulch (M) consisting of 3 ( three) namely, plastic mulch (M1), the biomass of bambara groundnut 6 tonnes/ha (M2), rice straw mulch 6 tonnes/ha (M3). Data analysis uses further analysis of variance if there is a significant difference in the F 5\% test. , followed by Duncan's multiple range test at the $5 \%$ level. To determine the closeness of the relationship between two or more variables, the correlation test used. The results showed that there was a significant interaction between the type of line and mulch treatment on the variable plant height at two, four, and six weeks after planting. The best plant height showed by the combination of the biomass of bambara groundnut 6 tonnes/ha and Gresik line mulch (M2G2).

Keywords : gresik strain, bambara groundnut, biomass of bambara groundnut.

\section{PENDAHULUAN}

Kacang bambara adalah salah satu tanaman jenis kacang-kacangan yang layak dikembangkan karena memiliki gizi yang banyak, kacang bambara tahan terhadap kekeringan dan sangat berpotensi sebagai tanaman pangan untuk memberikan ketahanan pangan di daerah kering. Kacang bambara tahan terhadap kekeringan, sehingga kacang bambara ini juga dikembangkan di pertanian Afrika (Berchie, J. N., Opoku, M., Adu-Dapaah, H., Agyemang, A., dan Sarkodie-Addo, J. 2012). Galur lokal mempunyai peranan penting untuk program pemuliaan tanaman. Galur lokal kacang bambara mempunyai potensi sangat tinggi untuk dikembangkan (Massawe et al., 2005). Di Indonesia

memiliki dua musim yaitu musim hujan dan musim kemarau. Pada kedua musim tersebut memiliki keuntungan untuk bercocok tanam. Menurut Supriyanto (2013) tanaman dengan kondisi air yang rendah dapat menghambat metabolisme seperti penyerapan nutrisi, menghambat pembelahan dan pembesaran sel, penurunan aktivitas enzim serta penutupan stomata sehingga pada pertumbuhan dan perkembangan tanaman menjadi terhambat. Redjeki (2004) kekeringan air saat postflowering pada tanaman kacang bambara dapat menurunkan pertumbuhan, dan menurunkan jumlah polong. Musim hujan yang tidak pasti dapat mengakibatkan hasil rendah. Kekurangan air dapat mengakibatkan polong menjadi sedikit, karena ginofor mengering sebelum terbentuk polong.

Pemanfaatan galur-galur lokal kacang bambara asal Gresik dan Jawa Barat diharapkan menghasilkan pertumbuhan yang lebih baik. Sehubungan dengan permasalahan diatas, maka diperlukan adanya penelitian tentang interaksi pemberian jenis galur dan mulsa terhadap pertumbuhan tanaman kacang bambara. Pemberian jenis mulsa diharapkan mampu mempertahankan kesediaan air sehingga dapat meningkatkan pertumbuhan tanaman kacang bambara.

\section{BAHAN DAN METODE Tempat dan Waktu}

Penelitian ini dilaksanakan di jln Pesantren Rt 01 Rw 02 Desa Pengulu, Kecamatan Sidayu, Kabupaten Gresik Jawa Timur. Pada ketinggian $7 \mathrm{~m}$ dpl. Penelitian ini 
dilakukan pada bulan Juni - Agustus 2020.

\section{Alat dan Bahan}

Bahan yang dibutuhkan : benih kacang bambara galur Jawa Barat, benih kacang bambara Galur gresik, mulsa plastik, mulsa jerami padi, mulsa brangkasan kacang bambara, dan pupuk kandang. Peralatan yang dibutuhkan meliputi : Termometer suhu max-min, RH meter dan Counter, rotary, alat tugal, cangkul, sabit, gembor, timba dan sprayer. Alat-alat pengukuran yang dibutuhkan meliputi : kamera, oven, timbangan manual, timbangan digital, jangka sorong, penggaris, meteran, plastik, buku dan alat tulis.

\section{Metode Penelitian}

Penelitian menggunakan Rancangan

\section{HASIL DAN PEMBAHASAN}

\section{Kondisi Lingkungan}

Salah satu faktor lingkungan yang
Acak Kelompok Faktorial dengan 2 faktor yang pertama jenis mulsa (M) dan faktor kedua asal Galur (G)

Kedua faktor dikombinasikan sehingga diperoleh 6 kombinasi perlakuan, dan diulang tiga kali, sehingga diperoleh 18 satuan percobaan. Notasi kombinasi perlakuan sebagai berikut :

$\mathrm{M}_{1} \mathrm{G}_{1}$ = Mulsa plastik + Galur Jawa Barat

$\mathrm{M}_{1} \mathrm{G}_{2}=$ Mulsa plastik + Galur Gresik $\mathrm{M}_{2} \mathrm{G}_{1}=$ Mulsa brangkasan kacang bambara 6 ton/ha + Galur Jawa Barat $\mathrm{M}_{2} \mathrm{G}_{2}=$ Mulsa brangkasan kacang bambara 6 ton/ha + Galur Gresik

$\mathrm{M}_{3} \mathrm{G}_{1}=$ Mulsa jerami padi 6 ton/ha + Galur Jawa Barat

$\mathrm{M}_{3} \mathrm{G}_{2}$ = Mulsa jerami padi 6 ton.ha + Galur Gresik

berpengaruh penting dalam pertumbuhan tanaman adalah kondisi lingkungan. Kondisi lingkungan pada saat penelitian disajikan pada tabel 1

Tabel 1. Tabel 4.1 Rerata Suhu Optimum $\left({ }^{\circ} \mathrm{C}\right)$, maximum $\left({ }^{\circ} \mathrm{C}\right)$, Minimum $\left({ }^{\circ} \mathrm{C}\right)$, Curah Hujan (mm) dan kelembaban tanah (\%).

\begin{tabular}{lcll}
\hline & \multicolumn{3}{c}{ Tahun2020 } \\
\cline { 2 - 4 } \multicolumn{1}{c}{ Kondisi Lingkungan } & Mei & Juni & Juli \\
\hline 1. Suhu & & & \\
Optimum & $24^{\circ} \mathbf{C}$ & $25^{\circ} \mathbf{C}$ & $27^{\circ} \mathbf{C}$ \\
Maximum & $33^{\circ} \mathbf{C}$ & $33^{\circ} \mathbf{C}$ & $32^{\circ} \mathbf{C}$ \\
Minimum & $26^{\circ} \mathbf{C}$ & $25^{\circ} \mathbf{C}$ & $24^{\circ} \mathbf{C}$ \\
2. Kelembapan Tanah & $40 \%$ & $55 \%$ & $40 \%$ \\
3. CH & $120 \mathrm{~mm}$ & $90 \mathrm{ml}$ & $90 \mathrm{ml}$ \\
\hline
\end{tabular}

Tabel 1 menunjukkan kondisi lingkungan di Kecamatan Sidayu Kabupaten Gresik. Setiap tanaman memiliki kondisi lingkungan yang berbeda. Pada kondisi lingkungan ini memiliki rerata suhu optimum $24-27$ ${ }^{\circ} \mathrm{C}$, suhu maximum $32-33{ }^{\circ} \mathrm{C}$, minimum $24-26^{\circ} \mathrm{C}$, kelembaban tanah 40-55 \%, dan Curah Hujan 90-120 $\mathrm{mm}$ 


\section{Variabel Pertumbuhan}

Pada Variabel pertumbuhan ini meliputi : laju perkecambahan, tinggi tanaman, jumlah daun, petiole, internode, daun tengah, bud flower, ginofor, peduncle, bunga pertama, dan bunga $50 \%$. Variabel pertama diamati adalah variabel laju perkecambahan. Pengamatan tinggi tanaman dan jumlah daun diamati minggu ke 2, 4, 6 dan 8. Rerata Variabel Pertumbuhan pada Interaksi Jenis Galur dengan Mulsa Terhadap Tanaman Kacang Bambara (VignaSubterranea (L.) Verdcourt) disajikan pada tabel 2

\section{Laju Perkecambahan}

Tabel 2 hasil uji DMRT 5\% variabel laju perkecambahan menunjukkan bahwa interaksi jenis galur dan mulsa tidak menunjukkan perbedaan nyata pada semua perlakuan. Sedangkan pada perlakuan jenis galur terdapat perbedaan sangat nyata perlakuan galur Jawa Barat dengan galur Gresik. Selain itu, tidak terdapat perbedaan nyata perlakuan mulsa plastik, mulsa brangkasan kacang bambara, dan mulsa jerami pada

\section{Tinggi Tanamn}

Tabel 2 hasil uji DMRT 5\% variable tinggi tanaman menunjukan bahwa interaksi jenis galur dan mulsa terdapat perbedaan sangat nyata pada umur pengamatan minggu ke 2 dan minggu ke 4. Terdapat perbedaan nyata minggu ke 6 pada interaksi jenis galur dan mulsa. Pada minggu ke 8 tidak terdapat perbedaan nyata interaksi jenis galur dan mulsa. Selain itu, pada perlakuan jenis galur menunjukkan perbedaan sangat nyata minggu ke 2, 4, 6 dan 8 pada perlakuan galur Jawa Barat dan galur Gresik. Sedangkan perlakuan jenis mulsa terdapat perbedaan sangat nyata perlakuan jenis mulsa pada minggu ke 2, 4, 6 dan 8 .

\section{Jumlah Daun}

Tabel 2 hasil uji DMRT 5\% menunjukkantidak terdapat perbedaan nyata interaksi mulsa dan galur pada semua umur pengamatan. Perlakuan galur menunjukan perbedaan sangat nyata pada variabel jumlah daun saat umur $2 \mathrm{mst}, 4 \mathrm{mst}, 6 \mathrm{mst}$ dan $8 \mathrm{mst}$. Selain itu, pada pemberian mulsa juga tidak menunjukan perbedaan nyata pada semua umur pengamatan.

\section{Panjang Petiole}

Tabel 2 hasil uji DMRT 5\% variabel pengamatan panjang petiole menunjukan bahwa interaksi jenis galur dan mulsa tidak menunjukkan perbedaan nyata. Sedangkan, perlakuan jenis galur terdapat perbedaan sangat nyata pada galur Jawa Barat dan galur Gresik. Selain itu, terdapat perbedaan sangat nyata pada mulsa plastik, mulsa brangkasan kacang bambara dan mulsa jerami padi 
Khanifah et al., Interaction of Strain...

Tabel 2. Rerata Variabel Pertumbuhan pada Interaksi Jenis Galur dengan Mulsa Terhadap Tanaman Kacang Bambara

\begin{tabular}{|c|c|c|c|c|c|c|c|c|c|c|c|c|c|c|c|c|c|}
\hline \multirow[t]{2}{*}{ Perlakuan } & \multirow[t]{2}{*}{ LP } & \multicolumn{4}{|c|}{$\begin{array}{l}\text { Umur Pengamatan Minggu } \\
\text { Setelah Tanam (Mst) }\end{array}$} & \multicolumn{4}{|c|}{$\begin{array}{c}\text { Umur Pengamatan Minggu Setelah } \\
\text { Tanam (Mst) }\end{array}$} & \multirow[t]{2}{*}{ Petiole } & \multirow[t]{2}{*}{ Internode } & \multirow[t]{2}{*}{ PD } & \multirow[t]{2}{*}{ PP } & \multirow[t]{2}{*}{ PBF } & \multirow[t]{2}{*}{ PG } & \multirow[t]{2}{*}{$\mathrm{BP}$} & \multirow{2}{*}{$\begin{array}{l}\text { Bunga } \\
50 \%\end{array}$} \\
\hline & & $2 \mathrm{mst}$ & $4 \mathrm{mst}$ & $6 \mathrm{mst}$ & $8 \mathrm{mst}$ & $2 \mathrm{mst}$ & $4 \mathrm{mst}$ & $6 \mathrm{mst}$ & $8 \mathrm{mst}$ & & & & & & & & \\
\hline $\mathrm{M}_{1} \mathrm{G}_{1}$ & 5.70 & 13.9 & 17.1 & 18.7 & 21.57 & 4.9 & 12.1 & 25.0 & 27.6 & 13.8 & 1.0 & 4.90 & 0.90 & 0.50 & 1.40 & 42.70 & 52.00 \\
\hline $\mathrm{M}_{1} \mathrm{G}_{2}$ & 8.00 & 17.93 & 21.3 & 23.43 & 25.50 & 4.03 & 7.87 & 19.07 & 21.43 & 16.5 & 1.63 & 8.10 & 1.02 & 0.57 & 1.39 & 51.00 & 62.33 \\
\hline $\mathrm{M}_{2} \mathrm{G}_{1}$ & 5.25 & 17.67 & 21.07 & 22.07 & 24.47 & 5.13 & 11.03 & 25.33 & 28.37 & 16.93 & 1.0 & 5.10 & 0.97 & 0.56 & 1,36 & 48.67 & 51.67 \\
\hline $\mathrm{M}_{2} \mathrm{G}_{2}$ & 7.14 & 18.57 & 22.07 & 26.47 & 28.60 & 4.37 & 11.03 & 21.87 & 24.97 & 19.57 & 1.22 & 7.90 & 1.08 & 0.61 & 1.47 & 51.33 & 60.33 \\
\hline $\mathrm{M}_{3} \mathrm{G}_{1}$ & 5.89 & 17.43 & 20.33 & 21.43 & 24.00 & 5.2 & 10.8 & 26.87 & 29.1 & 16.43 & 0.84 & 4.93 & 0.91 & 0.54 & 1.38 & 43.67 & 56.67 \\
\hline $\mathrm{M}_{3} \mathrm{G}_{2}$ & 7.20 & 17.47 & 20.6 & 22.03 & 24.77 & 4.5 & 9.77 & 19.27 & 22.5 & 16.27 & 1.09 & 7.97 & 1.02 & 0.58 & 1.44 & 48.33 & 59.00 \\
\hline $\begin{array}{l}\text { DMRT } \\
5 \%\end{array}$ & tn & $* *$ & $* *$ & $*$ & tn & tn & tn & tn & tn & tn & tn & tn & tn & tn & tn & tn & tn \\
\hline $\mathrm{G}_{1}$ & $5.61 \mathrm{a}$ & $16.32 \mathrm{a}$ & $19.5 \mathrm{a}$ & $20.73 a$ & 23.34 & $5.08 b$ & $11.30 \mathrm{~b}$ & $25.74 b$ & $28.36 b$ & $15.71 \mathrm{a}$ & $0.97 \mathrm{a}$ & $4.9 \mathrm{a}$ & 0.94 & 0.54 & 1.38 & $45.0 \mathrm{a}$ & $53.4 \mathrm{a}$ \\
\hline $\mathrm{G}_{2}$ & $7.57 b$ & $18.25 \mathrm{~b}$ & $21.68 b$ & $24.95 b$ & 27.05 & $4.20 \mathrm{a}$ & $9.45 \mathrm{a}$ & $20.47 \mathrm{a}$ & $23.20 \mathrm{a}$ & $18.03 \mathrm{~b}$ & $1.43 \mathrm{~b}$ & $8.0 \mathrm{~b}$ & 1.05 & 0.59 & 1.43 & $51.1 \mathrm{~b}$ & $61.3 b$ \\
\hline \multicolumn{18}{|l|}{ DMRT 5\% } \\
\hline $\mathrm{M}_{1}$ & 6.84 & $15.90 \mathrm{a}$ & $19.20 \mathrm{a}$ & $21.70 \mathrm{a}$ & 23.53 & 4.47 & 9.97 & 22.05 & 24.52 & $15.13 \mathrm{a}$ & 1.32 & 6.50 & 0.98 & 0.55 & 1.40 & 46.83 & 57.17 \\
\hline $\mathrm{M}_{2}$ & 6.20 & $18.12 \mathrm{c}$ & $21.57 \mathrm{c}$ & $24.27 \mathrm{c}$ & 26.53 & 4.75 & 11.03 & 23.6 & 26.67 & $18.25 \mathrm{c}$ & 1.15 & 6.50 & 1.02 & 0.58 & 1.41 & 50.00 & 56.00 \\
\hline $\mathrm{M}_{3}$ & 6.46 & $17.45 \mathrm{~b}$ & $20.47 b$ & $21.73 \mathrm{ab}$ & 24.38 & 4.85 & 10.28 & 23.07 & 25.8 & $16.35 b$ & 0.97 & 6.45 & 0.97 & 0.56 & 1.41 & 46.00 & 57.83 \\
\hline $\begin{array}{l}\text { DMRT } \\
5 \%\end{array}$ & tn & $* *$ & $* *$ & $* *$ & $* *$ & tn & tn & tn & tn & $* *$ & tn & tn & tn & tn & tn & tn & tn \\
\hline
\end{tabular}

Keterangan : LP (laju perkecambahan), PD (panjang daun), PP (panjang petiole), PBF (panjang bud flower), PG (panjang ginofor), BP (bunga pertama), tn (tidak nyata), * (nyata), ** (sangat nyata). 


\section{Panjang Internode}

Tabel 2 hasil uji DMRT 5\% variable panjang internode menunjukan bahwa tidak berbeda nyata perlakuan interaksi jenis galur dan mulsa pada semua perlakuan. Sedangkan perlakuan jenis galur menunjukkan perbedaan nyata pada galur Jawa Barat dan galur Gresik. Pada pemberian mulsa tidak menunjukkan perbedaan nyata pada variabel internode.

\section{Panjang Daung Tengah}

Tabel 2 hasil uji DMRT taraf signifikan $5 \%$ variable panjang daun tengah tidak terdapat perbedaan perlakuan interaksi jenis galur dan mulsa. Sedangkan pada jenis galur menunjukkan bahwa terdapat perbedaan sangat nyata perlakuan jenis galur Jawa Barat dan galur Gresik. Pada perlakuan jenis mulsa plastik, mulsa brangkasan kacang bambara, dan mulsa jerami padi tidak menunjukkan perbedaan nyata pada perlakuan panjang daun tengah.

\section{Panjang Peduncle}

Tabel 2 hasil analisis sidik ragam variabel panjang peduncle menunjukkan tidak terdapat perbedaan nyata pada semua perlakuan. Hasil uji DMRT 5\% variabel panjang peduncle pada perlakuan jenis galur dan mulsa tidak memiliki perbedaan nyata. jenis galur Jawa Barat tidak berbeda nyata dengan jenis galur Gresik. Pada jenis mulsa plastik, mulsa brangkasan kacang bambara, dan mulsa jerami padi tidak terdapat perbedaan nyata.

\section{Bud Flower}

Tabel 2 hasil uji DMRT taraf signifikasi 5\% menunjukkan bahwa pemberian perlakuan interaksi jenis galur dan mulsa tidak menunjukkan perbedaan nyata pada variabel bud flower. Selain itu, perlakuan jenis galur dan perlakuan jenis Mulsa juga tidak menunjukkan perbedaan nyata pada variabel bud flower.

\section{Ginofor}

Tabel 2 hasil uji DMRT $5 \%$ variable panjang ginofor menunjukkan bahwa tidak terdapat perbedaan nyata perlakuan interaksi jenis galur dan mulsa ada semua perlakuan pengamatan. Selain itu, jenis galur Jawa Barat dengan jenis galur Gresik tidak memiliki perbedaan nyata. Pada pemberian jenis mulsa juga tidak terdapat perbedaan nyata.

\section{Bunga Pertama}

Tabel 2 hasil uji DMRT 5\% variable bunga pertama menunjukkan bahwa perlakuan interaksi jenis galur dan mulsa tidak terdapat perbedaan nyata. Sedangkan pada perlakuan jenis galur Jawa Barat memiliki perbedaan nyata dengan jenis galur Gresik. Pada pemberian jenis mulsa plastik, mulsa brangkasan kacang bambara tidak memiliki perbedaan nyata dengan mulsa jerami padi.

\section{Bunga 50\%}

Tabel 2 hasil uji DMRT $5 \%$ variable bunga $50 \%$ menunjukkan bahwa perlakuan interaksi jenis galur dan mulsa tidak memiliki perbedaan nyata. Terdapat perbedaan sangat nyata pemberian galur Jawa Barat dan galur Gresik. Pada perlakuan jenis mulsa plastik, mulsa brangkasan kacang bambara dan mulsa jerami padi tidak memiliki perbedaan nyata. 
Uji Korelasi

\begin{tabular}{|c|c|c|}
\hline & LP & \\
\hline \multirow[t]{2}{*}{ jumlah daun $6 \mathrm{mst}$} & -0.68 & $* *$ \\
\hline & 0.00 & \\
\hline \multirow[t]{2}{*}{ tinggi tanaman $6 \mathrm{mst}$} & 0.46 & $*$ \\
\hline & 0.05 & \\
\hline \multirow[t]{2}{*}{ internode } & 0.46 & $*$ \\
\hline & 0.05 & \\
\hline \multirow[t]{2}{*}{ Petiole } & 0.23 & \\
\hline & 0.37 & \\
\hline \multirow[t]{2}{*}{ panjang daun tengah } & 0.77 & $*$ \\
\hline & 0.00 & \\
\hline \multirow[t]{2}{*}{ Ginofor } & 0.21 & \\
\hline & 0.40 & \\
\hline \multirow[t]{2}{*}{ bud flower } & 0.26 & \\
\hline & 0.29 & \\
\hline \multirow[t]{2}{*}{ peduncle } & 0.12 & \\
\hline & 0.63 & \\
\hline \multirow[t]{2}{*}{ bunga pertama } & 0.53 & $*$ \\
\hline & 0.02 & \\
\hline \multirow[t]{2}{*}{ bunga $50 \%$} & 0.59 & $* *$ \\
\hline & 0.01 & \\
\hline
\end{tabular}

Ket : hubungan searah (+), hubungan tidak searah (-), ** ( hubungan sangat erat), * (hubungan erat).

\section{Interaksi Pemberian Galur dan Mulsa pada Tanaman Kacang Bambara}

Pada penelitian ini mulsa brangkasan kacang bambara dan galur Gresik $\left(\mathrm{M}_{2} \mathrm{G}_{2}\right)$ memiliki rerata tertinggi pada variable tinggi tanaman. Hal ini sesuai dengan pernyataan Djukri, (2005) pada penelitiannya tanaman kacang tanah terdapat perbedaan nyata pada rata- rata tinggi tanaman yaitu 30,78 dengan perlakuan bobot serasah daun 50 gram. Daun-daunan yang tua lebih banyak mengandung kalsium dibandingkan daun muda. Kalsium memperkuat dinding sel, kalsium juga berhubungan dengan keseimbangan ion-ion kalium. Namun, ini tidak sejalan dengan penelitian Ginting dan Mariati, (2014) pada penelitiannya menunjukkan bahwa pemberian unsur kalium tidak memiliki perbedaan nyata pada semua variabel pertumbuhan. Hal ini bisa disebabkan karena faktor lingkungan seperti, curah hujan yang terlalu tinggi dan pemberian unsur kalium rendah sehingga tidak memenuhi kebutuhan tanaman kacang tanah.

Menurut Buckman dan Brandy, (2000) menyatakan bahwa mulsa organik seperti brangkasan kacang, jerami padi dan mulsa lainnya, mampu meningkatkan jumlah bahan organik dan unsur hara ke dalam tanah. Menurut widodo el al, (2017) mulsa biasanya digunakan petani untuk penutup tanah agar tidak terjadi penguapan yang berlebihan pada tanaman. Mulsa juga menyebabkan lembabnya permukaan tanah sehingga membentuk tanaman tersebut tumbuh dengan baik. Namun, mulsa brangkasan kacang bambara dan mulsa jerami memiliki nilai lebih tinggi dibandingkan dengan mulsa plastik.

\section{Pengaruh Pemberian Jenis Galur terhadap Pertumbuhan Tanaman Kacang Bambara \\ Variabel pengamatan laju} perkecambahan menunjukkan bahwa kacang bambara galur Gresik memiliki rerata tertinggi. variabel berbunga 50\% tertinggi juga ditunjukkan pada galur Gresik. Menurut Nugraha, Ardiarini, \& Kuswanto, (2018) galur lokal memiliki potensi yang lebih tinggi untuk dikembangkan. Menurut Redjeki, (2003) Seleksi pada warna biji kacang bambara adalah upaya untuk menyeleksi tanaman berdasarkan fenotip yang sama sehingga 
menghasilkan galur murni.

Pengamatan Jumlah daun menunjukkan bahwa kacang bambara galur Jawa Barat. Hal ini disebabkan karena keragaman genetika yang berbeda antara galur Jawa Barat dengan galur Gresik. Pengamatan ini sejalan dengan Yuliawati et al, (2018), pada penelitiannya Galur Jawa Barat memiliki jumlah daun yang lebih banyak dengan kisaran antara 33,89 72,65 daun dengan nilai tengah 49,22 daun pada umur 112 hari.

Variabel tinggi tanaman Galur Gresik memiliki rerata tertinggi. Hal ini bisa disebabkan perbedaan genetika antara galur Jawa Barat dan galur Gresik. Menurut Nadia, (2014) kacang bambara galur Jawa Barat variabel tinggi tanaman memiliki nilai cukup rendah dari galur kontrol.

Variabel panjang petiole kacang bambara galur Gresik $\left(\mathrm{G}_{2}\right)$ memiliki rerata tertinggi 18,03. Menurut Febriane et,al (2011) Nilai rata-rata karakter pada panjang petiole galur Gresik memiliki rata-rata tertinggi yaitu 15,89 . Sedangkan pada galur Jawa Barat memiliki rata-rata tertinggi yaitu 14,86 .

Variabel internode uji lanjut kacang bambara galur Gresik $\left(\mathrm{G}_{2}\right)$ menunjukan rerata tertinggi yaitu 1,43 . Menurut Febriane et,al(2011) Dari seleksi beberapa galur, galur Gresik memiliki panjang internode yaitu 2,02 dan galur Jawa Barat memiliki panjang internode yaitu 1,98. Galur Gresik memiliki panjang internode lebih ditinggi dari galur Jawa Barat.

Variabel panjang daun tengah galur Gresik $\left(\mathrm{G}_{2}\right)$ memiliki rerata tertinggi yaitu 8,00 Jenis galur Jawa Barat dan galur Gresik memang meimiliki karakteristik yang berbeda.
Austi et al, (2012) bahwa panjang daun yang lebih besar meningkatkan penyerapan sinar matahari secara optimal dan memaksimalkan fotosintesis untuk menghasilkan fotosintat yang lebih besar.

Variabel pengamatan panjang ginofor, peduncle, dan bud flower tidak memiliki perbedaan nyata pada perlakuan jenis galur. Pada saat pengamatan $8 \mathrm{mst}$ diduga panjang ginofor, peduncle, dan bud flower masih muda untuk diamati. Selain disebabkan oleh faktor lingkungan pada variabel pengamatan panjang ginofor, petiole dan bud flower juga dipengaruhi oleh faktor genetik pada fase vegetatif maupun fase generatif.

\section{Pengaruh Pemberian Jenis Mulsa terhadap Pertumbuhan Tanaman Kacang Bambara}

Variabel tinggi tanaman dan petiole memiliki rerata tertinggi pemberian mulsa brangkasan kacang bambara $\left(\mathrm{M}_{2}\right)$. Jumlah brangkasan kacang bambara yang melimpah sebagai bahan kompos memiliki residu kualitas tinggi. Menurut Solihah, dan Sugianto (2016), Kacang tanah memiliki kandungan $\mathrm{C} / \mathrm{N}$ ratio sebesar 12,55, kandungan nitrogen 2,72\%, kandungan bahan organik $63,75 \%$, kandungan lignin $10,58 \%$ dan kandungan polifenol 5,98\%.

Tidak terdapat perbedaan nyata pemberian jenis mulsa pada variabel pengamatan laju perkecambahan, jumlah daun, panjang internode, panjang daun tengah, panjang peduncle, bud flower, ginofor, bunga pertama dan bunga $50 \%$. Hal ini dapat disebabkan karena beberapa faktor diantaranya kurangnya pemberian dosis mulsa, sehingga unsur hara 
makro dan mikro rendah dan kurang terpenuhi. Selain itu juga karena faktor lingkungan pada pemberian jenis mulsa. Menurut Purwowidodo, (2001) salah satu akibat melepuhnya berbagai bahan mulsa organik akan menghasilkan bahan-bahan organik, sehingga apa yang dibutuhkan oleh tanaman bisa terpenuhi.

\section{Hubungan Dua Variabel}

Pada jumlah daun 6 mst dan laju perkecambahan memiliki hubungan sangat erat dan tidak searah. Ini menunjukkan bahwa galur yang makin cepat berkecambah maka menghasilkan jumlah daun yang lebih banyak. Pada tinggi tanaman 6 mst dan laju perkecambahan memiliki hubungan erat dan searah. Pada internode dan laju perkecambahan memiliki hubungan yang nyata dan searah. Pada panjang daun dan laju perkecambahan memiliki hubungan sangat erat dan searah. Pada bunga pertama dan laju perkecambahan memiliki hubungan erat dan searah. Pada bunga $50 \%$ dan laju perkecambahan memiliki hubungan sangat erat dan searah. Semakin cepatnya laju perkecambahan maka tanaman akan melakukan fotosintesis pada daun yaitu pada sel mesofil sehingga tanaman cepat membentuk sempurna. Sehingga, mempercepat tumbuhnya tinggi tanaman, internode, panjang daun, bunga pertama, dan bunga $50 \%$. Tanaman yang melakukan proses fotosintesis lebih tinggi akan memiliki banyak daun. Menurut Prawinata et,al (1991) Pemberian unsur nitrogen dapat meningkatkan laju perkecambahan, sehingga dapat memacu pertumbuhan vegetatif. Transportasi hara dari akar ke daun, translokasi asimilat dari daun ke seluruh jaringan tanaman. Hasil fotosintesis akan membentuk organ tanaman pada daun dan batang. Semakin banyak cahaya yang masuk pada tanaman maka fotosintesis yang dihasilkan juga semakin tinggi. Maka proses laju perkecambahan juga akan tumbuh cepat (Firda, 2009). Proses fotosintesis tidak hanya dilakukan pada daun saja tetapi dilakukan pada batang tanaman yang mengakibatkan panjang pada daun dan tinggi tanaman. Unsur nitrogen pada tanaman dapat merangsang secara keseluruhan khususnya pada ukuran daun dan panjang batang (Gardner, et al 1991).

\section{SIMPULAN}

Terdapat interaksi nyata jenis galur dan mulsa terhadap pertumbuhan tanaman kacang bambara (Vigna subterranea (L). Verdcourt). Hal ini ditunjukkan oleh variabel tinggi tanaman umur 2, 4, 6 minggu setelah tanam. Kombinasi perlakuan mulsa brangkasan kacang bambara dan galur Gresik ( $\left.\mathrm{M}_{2} \mathrm{G}_{2}\right)$ mampu menunjukkan pertumbuhan terbaik pada tinggi tanaman.

\section{SARAN}

Petani disarankan melakukan upaya menanam tanaman kacang bambara pada musim kemarau dengan memanfaatkan mulsa brangkasan kacang bambara. Disarankan melakukan penelitian lebih lanjut pengaruh berbagai dosis mulsa brangkasan kacang bambara terhadap pertumbuhan dan hasil tanaman.

DAFTRA PUSTAKA

Austi, I.R., Damanhuri, D. and Kuswanto, K., 2014. Keragaman dan Kekerabatan 
Khanifah et al., Interaction of Strain...

pada Proses Penggaluran Kacang Bogor (Vigna subterranean L. Verdcourt) Jenis Lokal. Jurnal Produksi Tanaman, 2(1).

Berchie, J. N., Opoku, M., AduDapaah, H., Agyemang, A., \& Sarkodie-Addo, J. (2012). Evaluation Of Five Bambara Groundnut(Vigna Subterrane (L.) Verdc.) Landraces To Heat And Drought Stress At TonoNavrongo, Upper East Region Of Ghana. African Journal of Agricultural Research, 7(2), 250-256.

Buckman, H. O. dan N. C. Brandy, 2000. Ilmu Tanah (Terjemahan Soegiman).

Djukri, D., 2005. Pengomposan Dan Efek Kompos Serasah Daun Acasia Mangium L Terhadap Pertumbuhan Dan Produksi Kacang Tanah INOTEKS 9(2).

Febriani, H. (2011). Potensi Genetik dan Penyusunan Deskripsi Galur Kacang Bambara (Vigna subterranea (L.) Verdcourt) (Doctoral dissertation, Universitas Brawijaya.

Firda, Y. 2009. Respon tanaman kedelai (Glycine max (L.) Merril) terhadap cekaman kekurangan air dan pemupukan kalium. Skripsi Fakultas Pertanian Universitas Riau : Pekanbaru

Gardner, F. P. Pearce RB. Mitchell RL. 1991 Fisiologi Tanaman Budidaya (Alih bahasa: $H$. Susilo). Universitas Indonesia Press. Jakarta.

Ginting, J. and Mariati, M., 2014.
Respons Pertumbuhan Dan Produksi Tanaman Kacang Tanah (Arachis hypogaea L.) Terhadap Pemberian Paclobutrazol Dan Pupuk Kalium. Jurnal Agroekoteknologi Universitas Sumatera Utara, 2(4), p.101943.

Massawe, F. J., Mwale, S. S., AzamAli, S. N., \& Roberts, J. A. (2005). Breeding in bambara groundnut (Vigna subterranea (L.) Verdc.): $\quad$ strategic considerations. African Journal of Biotechnology, 4(6), 463-471.

Nabila N. 2014. Seleksi galur murni lanras kacang bogor (Vigna subterranea L.) asal Sukabumi [skripsi]. Bogor [ID] : Institut Pertanian Bogor.

Nugraha, A.A., Ardiarini, N.R. and Kuswanto, K., 2018. Uji Keseragaman Galur Dan Kekerabatan Antar Galur Kacang Bogor (Vigna Subterranea (L.) Verdc.) Hasil Single Seed Descent Kedua. Jurnal Produksi Tanaman, 5(7).

Prawiranata, W., S. Harran, \& P.Tjondronegoro. 1991. Dasardasar Fisiologi Tumbuhan. Jurusan Biologi Fakultas MIPA, IPB. Bogor.

Purwowidodo. 2001. Teknologi Mulsa. Dewa Ruci Press : Jakarta

Redjeki, E. S. (2003). Pengaruh Seleksi Galur Murni pada Populasi Campuran Terhadap Hasil Tanaman Kacang Bogor (Vigna Subterranea (L.) Verdcourt). Agrofish, 3(2), 97105. 
Khanifah et al., Interaction of Strain...

Redjeki, E. S. (2004). Pertumbuhan Lanras. JURNAL AGRONIDA, dan Hasil Tanaman Kacang Bogor (Vigna Subterranea (L.) 4(2). Verdcourt) Galur Gresik dan Bogor pada Berbagai Warna Biji. Fakultas Pertanian, Universitas Muhammadiyah Gresik.

Solihah, A.danSugianto,A.2016.

Prosiding Seminar Hasil Penelitian Tanaman Aneka Kacang dan Umbi. Pengaruh Rekayasa Kualitas Residu Kedelai Berlabel $15 \mathrm{~N}$ terhadap Serapan dan Recovery $N$ Tanaman Jagung.2(2): 80-99.

Supriyanto, B. (2013). Pengaruh Cekaman Kekeringan Terhadap Pertumbuhan dan Hasil Padi Gogo Lokal Kultivar Jambu. J. 12 (1) : 7782.

Widodo, K.J., Yunus, M. and Shahabuddin, S., 2017. Pengaruh penggunaan beberapa mulsa terhadap serangan ulat bawang Spodoptera exigu (Lepidoptera Noctuidae) pada tanaman bawang merah (Allium ascalonicum) di desa bolu pountu jaya kecamatan sigi biromaru kabupaten sigi. Agroland: Jurnal Ilmu-ilmu Pertanian, 21(2), pp. 104-108.

Yuliawati, Y., Wahyu, Y., Surahman, M. and Rahayu, A., 2019. Genetic Variation and Agronomic Characters of Bambara Groundnut (Vigna subterranea L. Verdc.) Lines Results of Pure Line Selection from Sukabumi 